\title{
Determination of Critical Load in a Nonuniform Circular Steel Column under the Eccentric Axial Load
}

\author{
Stanislav Kotšmíd, ${ }^{1}$ Chang-Hung Kuo, ${ }^{2}$ and Pavel Beňo ${ }^{1}$ \\ ${ }^{1}$ Faculty of Environmental and Manufacturing Technology, Technical University in Zvolen, 96001 Zvolen, Slovakia \\ ${ }^{2}$ College of Science and Technology, National Chi Nan University, Puli, Nantou 54561, Taiwan
}

Correspondence should be addressed to Stanislav Kotšmíd; stanislav.kotsmid@gmail.com

Received 28 February 2016; Accepted 15 June 2016

Academic Editor: Xiangyu Meng

Copyright (C) 2016 Stanislav Kotšmíd et al. This is an open access article distributed under the Creative Commons Attribution License, which permits unrestricted use, distribution, and reproduction in any medium, provided the original work is properly cited.

\begin{abstract}
The purpose of this paper is to determine a critical load for a nonuniform circular steel tube under eccentrically axial load. The circular tube has variable cross section at flattened ends with existing holes used for connection between members. Three different cases of eccentricities are studied with the drilled holes either on the same side or on the opposite side of column axis. The critical load is calculated from the differential equation of deflection curve which is solved by the power series and Runge-Kutta method. In addition, the loading tests were performed on a total of 180 specimens with different diameters, slenderness, and connection. The calculated results are compared and shown in a good agreement with those obtained from the experimental results. The results also show that the critical load decreases rapidly even at a small value of eccentricity and thus may have a significant effect on the load-carrying capacity.
\end{abstract}

\section{Introduction}

Space trusses have been widely used in engineering structures as construction industry imposing increasingly demanding requirements on safety design of light weight structures at low cost. The truss system is mainly composed of long steel members connected to each other at nodes to form the framework structures. The determination of critical load is essential to assess the reliability and safety of space truss structures.

The steel members used in truss systems are generally in circular hollow section for their adequate behaviour under both tension and compression [1]. However, the insufficient flat surface of circular profile for rivets or bolts placement creates challenging issues in the connection between steel members. Various patented designs of connection mechanisms have been proposed for the space truss systems such as Triodetic, Nodus, Mero, Okta, " $V$ ", processing of tube ends by milling and mutual welding, or simply connection and welding by a sheet insertion into the undercut tube ends $[2,3]$.
Compared to the complex modifications of tube ends, the staking end-flattened tubes fastened by large bolts appear to be relatively simple and have been widely used due to easy installation and cost saving [1]. The flattened ends, however, also present some disadvantages such as nodal eccentricities and loss of stiffness due to reduced cross section at flattened ends. The nodal eccentricities could substantially increase the bending moment, and the misalignment between drilled holes and column axis could result in eccentrically axial load that has vital effects on the critical load.

The behaviour of a column with different cross section subjected to eccentric load has been studied such as circular tubular column [4], elliptical hollow column [5], square and rectangular hollow columns [6], and the battened column composed of L-profiles under uniaxial and biaxial loads [7]. The tube column using the outer encasing thin-walled steel tube containing the other tubular columns is researched in [8], where the average confining stress in the mentioned columns with small eccentricity is approximately equal to that in columns under axial load. Often used T-profiles and 
TABLE 1: Tested variants of steel tubes.

\begin{tabular}{lccc}
\hline Connection & $d_{\text {ext }}(\mathrm{mm})$ & $l(\mathrm{~mm})$ & Number of specimens \\
\hline A & & $452,498,548$, & 5 specimens for each \\
B & 12 & $594,640,688$ & variant \\
C & & & \\
\hline A & & $534,588,646$, & 5 specimens for each \\
B & 14 & $704,756,812$ & variant \\
C & & & \\
\hline
\end{tabular}

square profiles in concurrent with I-profile which occur in the buildings are studied in $[9,10]$. The papers discuss how the eccentricity can affect the behaviour of specific columns. Due to a minimum mass requiring in the practice, crushing failures in thin-walled columns appear there, especially under the eccentric compression. As it was studied in [11], the eccentricity can increase the number of failure points where the plastic flow of material occurs, which is also dangerous.

The incentive to writing this paper was the lifting platform constructional design created at the Department of Mechanics, Mechanical Engineering and Design which was registered as a utility model in The Industrial Property Office of the Slovak Republic [12]. This platform consists of the circular tubes with flattened ends. Some theory and simplifications of the critical load calculation were published in [13-15]. In all cases, only centrically loaded column was considered. Owing to this, the requirement to calculate the critical load under the eccentric axial load was created.

To study the effect of eccentricity on the column behaviour, three different cases of eccentricity are considered in this paper: one connecting hole off the column axis, both connecting holes off and on the same side of column axis, and two connecting holes on the opposite side of column axis. The governing equation for loading of nonuniform circular column under eccentrically axial load is reduced to a differential equation of the fourth order which is solved by the power series and Runge-Kutta methods to calculate the critical load. The loading tests were also conducted to compare with theoretical results.

\section{Experimental Investigation}

The steel tubes with circular cross section are flattened at both ends where the length of the flattened portion is $1.5 \cdot d_{\text {ext }}$; $d_{\text {ext }}$ is external diameter of the circular cross section as shown in Figure 1. A connecting hole with a diameter of $7 \mathrm{~mm}$ was drilled at flattened portion; the centre of the hole is located at $0.75 \cdot d_{\text {ext }}$ from each end.

The loading tests were conducted on the steel tubes with various diameters and lengths. Totally 180 specimens were tested in the variants given in Table 1 . The values of eccentricity were $1.8 \mathrm{~mm}$ for a diameter of $12 \mathrm{~mm}$ and $2.8 \mathrm{~mm}$ for a diameter of $14 \mathrm{~mm}$.
TABLE 2: The mechanical characteristics of the steel S355.

\begin{tabular}{lc}
\hline Yield strength & $\min .355 \mathrm{MPa}$ \\
Tensile strength & $470-630 \mathrm{MPa}$ \\
Young's modulus & $2.1 \cdot 10^{5} \mathrm{MPa}$ \\
Shear modulus & $8 \cdot 10^{4} \mathrm{MPa}$ \\
Poisson's ratio & 0.3 \\
Density & $7850 \mathrm{~kg} \cdot \mathrm{m}^{-3}$ \\
Elongation & $\min .22 \%$ \\
Hardness & $\max .190 \mathrm{HB}$ \\
Impact strength (longitudinal) & $27 \mathrm{~J}$ at $+20^{\circ} \mathrm{C}$ \\
Coefficient of linear thermal expansion & $11.7 \cdot 10^{-6} \mathrm{~K}^{-1}$ \\
\hline
\end{tabular}

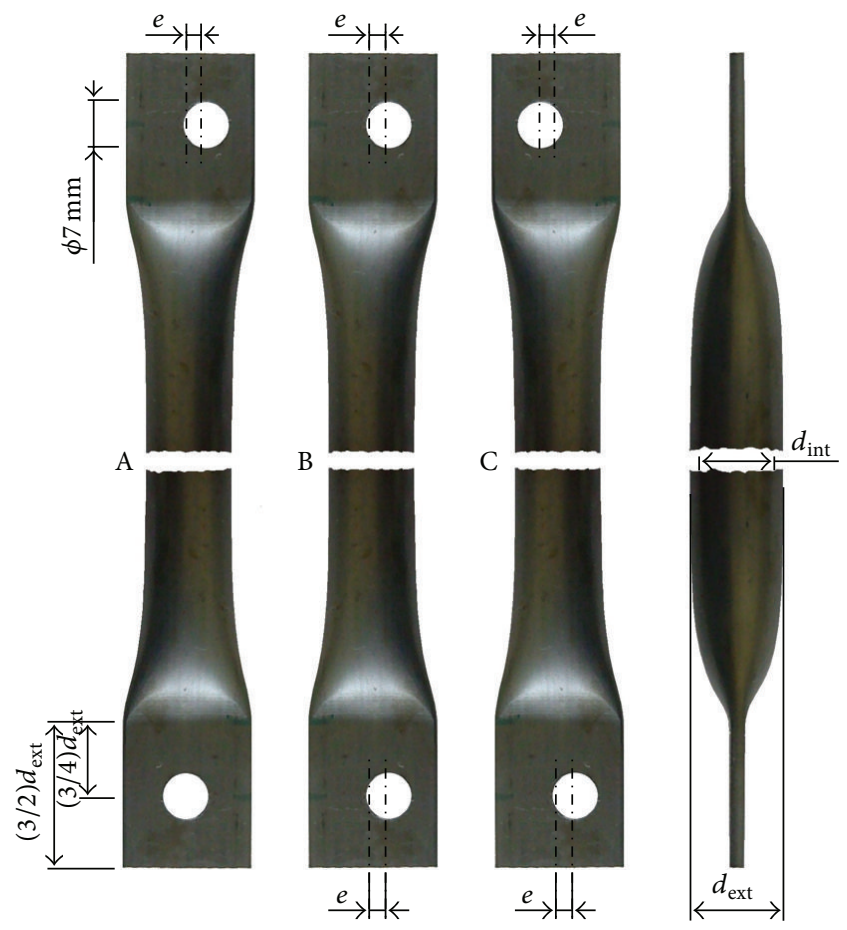

FIgURE 1: The steel tubes with flattened ends.

The tested specimens were made of S355 constructional steel with the tangent Young's modulus $E=210 \mathrm{GPa}$ according to the standard EN 10020. The mechanical characteristics of the steel S355 are given in Table 2.

The loading test of steel tubes was performed on the universal machine Testometric M500-100 CT, as shown in Figure 2 where an axial force was gradually loaded on the specimen mounted on the fixture. The displacement sensors were supplied with stabilized power and the data were recorded by NI USB 6008 and processed by LabView and winTest software.

The courses of the axial load in dependence of lateral displacement for a diameter $d_{\text {ext }}=14 \mathrm{~mm}$ and $l=812 \mathrm{~mm}$ are shown in Figure 3. 


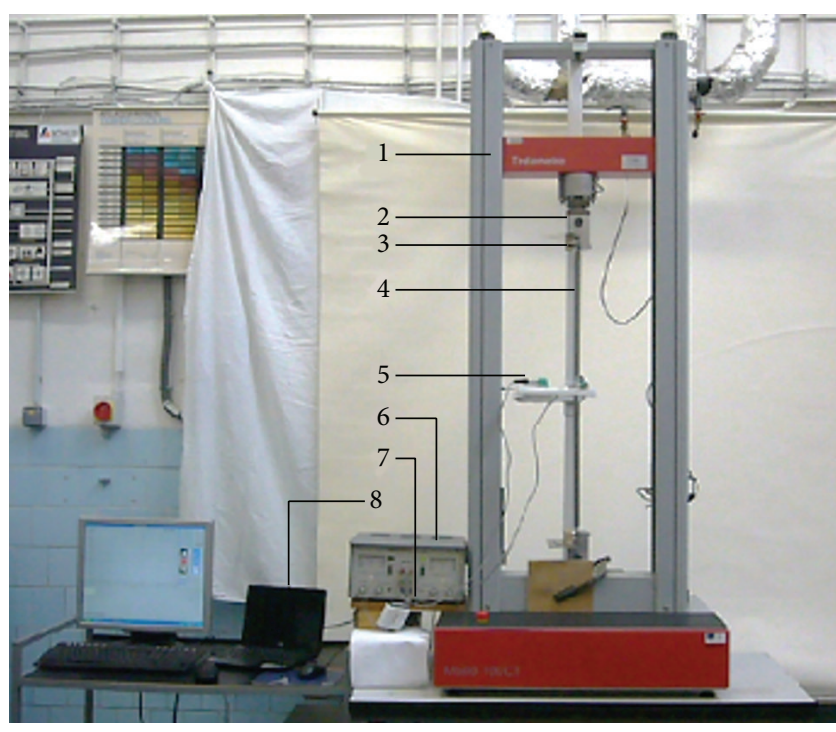

FIGURE 2: Experimental measurement. 1: Testometric M500-100 CT; 2: fixtures; 3: bolts; 4: specimen; 5: displacement sensors; 6: stabilized power supply; 7: NI USB 6008; 8: PC.

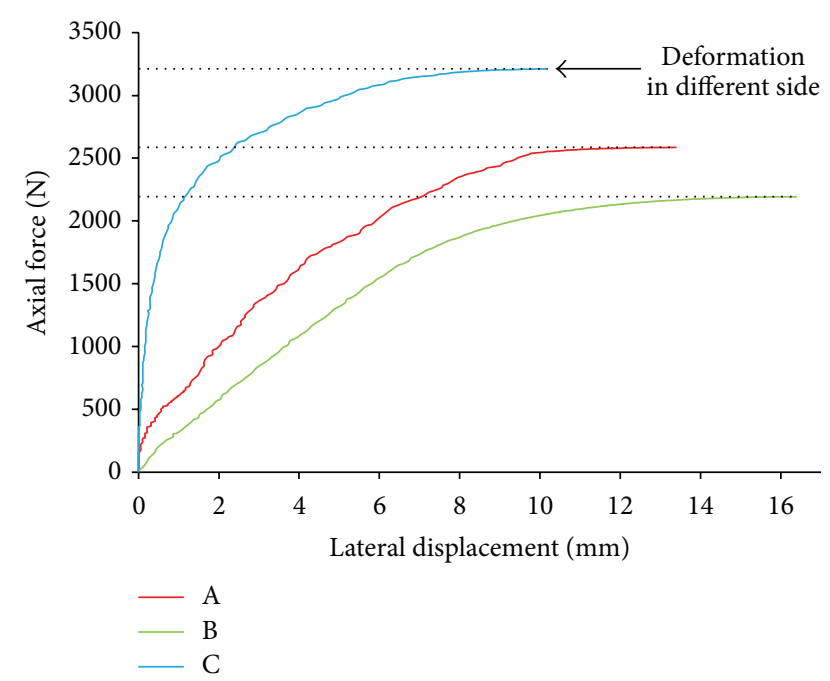

FIgURE 3: Output from the machine with determination of maximum axial force.

\section{Mathematical Formulation}

The governing differential equation for the axial loaded column with an eccentricity of connection and variable cross section can be derived from the equilibrium of moment as follows:

$$
\begin{array}{r}
\frac{d^{2}}{d x^{2}}\left[E I(x) \frac{d^{2}}{d x^{2}}(w(x)+e(x))\right] \\
+N \frac{d^{2}}{d x^{2}}(w(x)+e(x))=0
\end{array}
$$

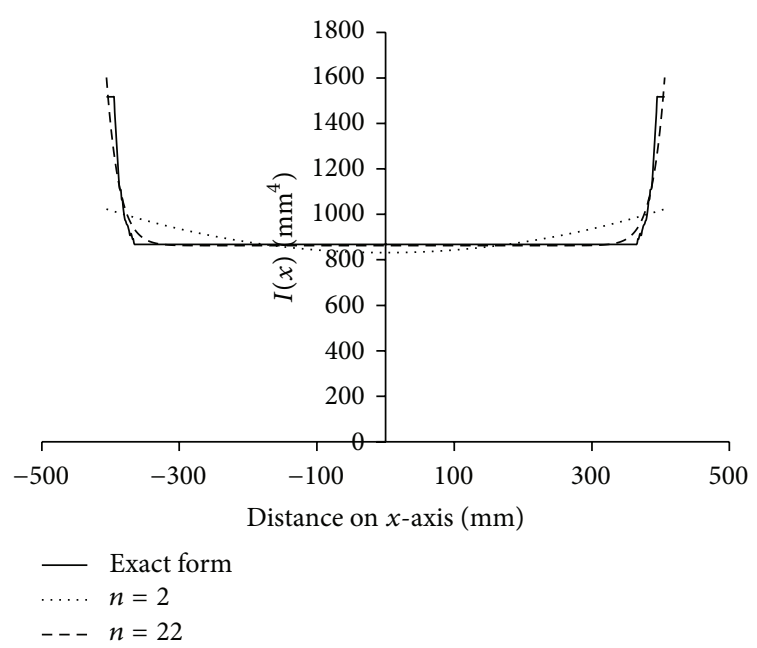

FIGURE 4: The measured and approximated moment of inertial along the steel tube for $d_{\text {ext }}=12$ and $l=812 \mathrm{~mm}$.

where $E I(x)$ is the flexural rigidity, $e(x)$ is the eccentricity, and $N$ is the axial force. The value of eccentricity is a constant in the case $\mathrm{B}$ and a linear function of a variable $x$ in cases $\mathrm{A}$ and $\mathrm{C}$. We do not need to know its accurate form, because it takes a zero value applying two derivatives. Owing to the tube length, the value of eccentricity is relatively small; therefore the angle of axial force rotation against the tube axis is negligible. The differential equation (1) can be rewritten as follows:

$$
\begin{aligned}
& I(x) \frac{d^{4}}{d x^{4}} w(x)+2 I^{\prime}(x) \frac{d^{3}}{d x^{3}} w(x)+I^{\prime \prime}(x) \frac{d^{2}}{d x^{2}} w(x) \\
& +\lambda \frac{d^{2}}{d x^{2}} w(x)=0,
\end{aligned}
$$

where $\lambda=N / E$ is the eigenvalue to be determined. Both analytical and numerical solutions for the differential equation are derived next. Analytical solution is derived based on the power series method while numerical solution is obtained by using the Runge-Kutta method.

The moment of inertial of the steel tube is sharply decreased from the flattened portion to the circular cross section as shown in Figure 4. To derive analytical solution for (2), the moment of inertial is approximated by a polynomial as follows:

$$
I(x)=a_{1} x^{n}+a_{0},
$$

where $n$ is an even number due to symmetry of moment of inertia. For the numerical solution, the exact values of moment of inertial measured every $1 \mathrm{~mm}$ along the steel tube were used in the solutions of (2).

The boundary conditions for the individual cases are built on the basis of mechanical schemes in Figures 5-7. 

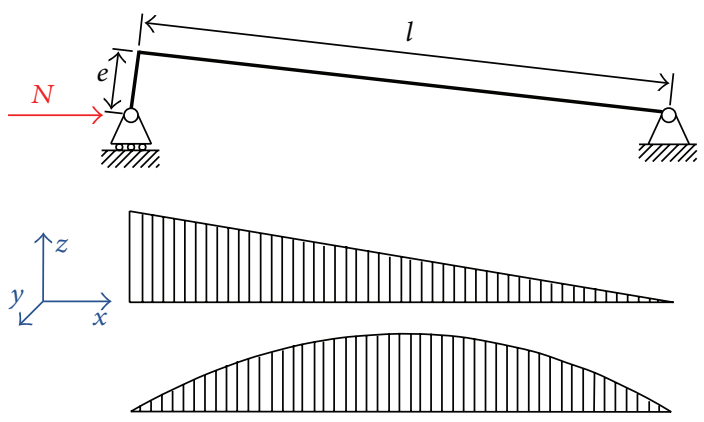

FIgUre 5: The bending moments scheme, case A.
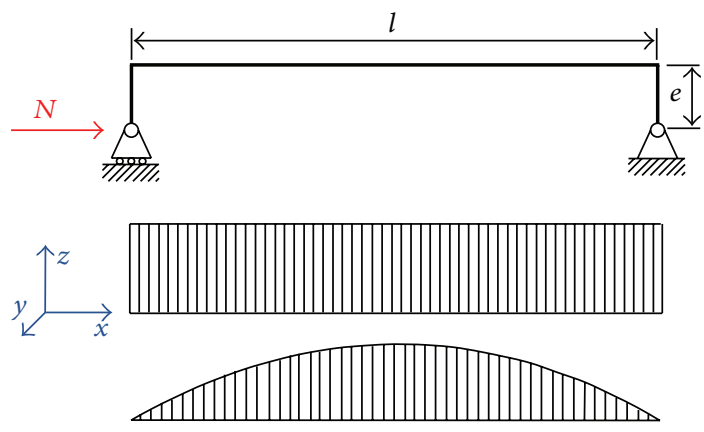

FIgure 6: The bending moment scheme, case B.

According to the previous schemes, the boundary conditions are determined:

(i) case A: $w\left( \pm \frac{l}{2}\right)=0$;

$$
\begin{aligned}
& w^{\prime \prime}\left(-\frac{l}{2}\right)=\frac{\lambda e}{I} ; \\
& w^{\prime \prime}\left(\frac{l}{2}\right)=0,
\end{aligned}
$$

(ii) case B: $w\left( \pm \frac{l}{2}\right)=0$;

$$
w^{\prime \prime}\left( \pm \frac{l}{2}\right)=\frac{\lambda e}{I},
$$

(iii) case C: $w\left( \pm \frac{l}{2}\right)=0$;

$$
\begin{aligned}
& w^{\prime \prime}\left(-\frac{l}{2}\right)=\frac{\lambda e}{I} \\
& w^{\prime \prime}\left(\frac{l}{2}\right)=-\frac{\lambda e}{I} .
\end{aligned}
$$

The solution of differential equation (2) can be expressed in power series form:

$$
w(x)=\sum_{i=0}^{\infty} c_{i} x^{i}
$$

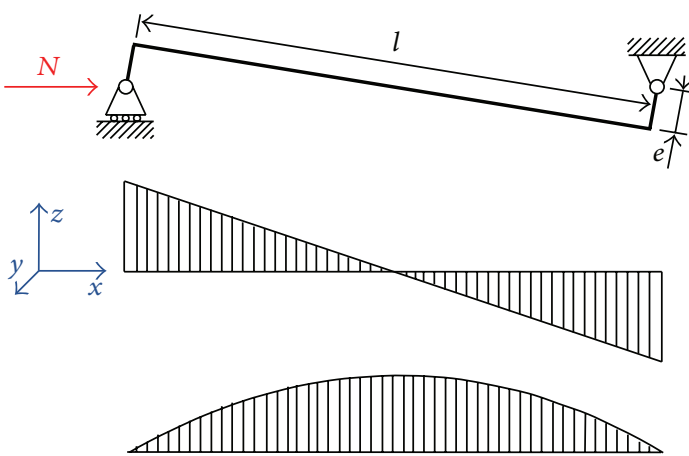

FIgURE 7: The bending moments scheme, case C.

By substituting (7) into (2), a series equation in terms of $x$ can be obtained as follows:

$$
\begin{aligned}
& \sum_{i=-2}^{\infty}\left\{c_{i+2}\left[a_{1}(i+1)(i+2)+\lambda\right]+c_{i+4} a_{0}(i+3)(i+4)\right\} \\
& \quad=0 .
\end{aligned}
$$

By regrouping the power of $x$, a recurrence formula for the coefficients $c_{i}, i=4,5,6, \ldots$, can be derived as follows:

$$
c_{i+4}=-\frac{c_{i+2}\left[\lambda+a_{1}(i+1)(i+2)\right]}{a_{0}(i+3)(i+4)},
$$

where the coefficients $c_{i}, i=0 \sim 3$, and the eigenvalue $\lambda$ remain to be determined. By substituting the recurrence formula into power series, the lateral displacement $w(x)$ and its first and second derivatives can be obtained as follows:

$w(x)$

$$
\begin{gathered}
=c_{0}+c_{1} x+c_{2}\left\{x^{2}+\sum_{i=2}^{\infty}\left[x^{2 i} \prod_{j=0}^{i-2} s_{j}(\lambda)\right]\right\} \\
+c_{3}\left\{x^{3}+\sum_{i=2}^{\infty}\left[x^{2 i+1} \prod_{j=0}^{i-2} t_{j}(\lambda)\right]\right\},
\end{gathered}
$$

$w^{\prime}(x)$

$$
\begin{aligned}
& =c_{1}+c_{2}\left\{2 x+\sum_{i=2}^{\infty}\left[2 i x^{2 i-1} \prod_{j=0}^{i-2} s_{j}(\lambda)\right]\right\} \\
& +c_{3}\left\{3 x^{2}+\sum_{i=2}^{\infty}\left[(2 i+1) x^{2 i} \prod_{j=0}^{i-2} t_{j}(\lambda)\right]\right\},
\end{aligned}
$$

$w^{\prime \prime}(x)$

$$
\begin{aligned}
= & c_{2}\left\{2+\sum_{i=2}^{\infty}\left[2 i(2 i-1) x^{2 i-2} \prod_{j=0}^{i-2} s_{j}(\lambda)\right]\right\} \\
& +c_{3}\left\{6 x+\sum_{i=2}^{\infty}\left[(2 i+1)(2 i) x^{2 i-1} \prod_{j=0}^{i-2} t_{j}(\lambda)\right]\right\},
\end{aligned}
$$


where

$$
\begin{aligned}
& s_{j}(\lambda)=-\frac{\lambda+a_{1}(2 j+1)(2 j+2)}{a_{0}(2 j+3)(2 j+4)}, \\
& t_{j}(\lambda)=-\frac{\lambda+a_{1}(2 j+2)(2 j+3)}{a_{0}(2 j+4)(2 j+5)} .
\end{aligned}
$$

Even one additional condition is needed to certain 5 unknown variables $c_{0}, c_{1}, c_{2}, c_{3}$, and $\lambda$. It is obtained by allowed stress definition in a certain place (in our case $\sigma=360 \mathrm{MPa}$ ). The question is in which place this condition will be chosen. Let us assume the highest deformation in a place around the middle of the rod. One side of a tube will be loaded by a tension; the second one will be loaded by a pressure. Overloading the allowed stress on a tension side will be the most dangerous state. This condition is written as

(i) case A: $\sigma=\frac{\lambda E\left(w_{\max }+e / 2-e x_{\max } / l\right)}{S}-\frac{\lambda E}{A}$,

(ii) case B: $\sigma=\frac{\lambda E\left(w_{\max }+e\right)}{S}-\frac{\lambda E}{A}$,

(iii) case C: $\sigma=\frac{\lambda E w_{\max }}{S}-\frac{\lambda E}{A}$,

where $x_{\max }$ is a distance of $w_{\max }$ measured from the middle of the rod.

On the basis of previous equations, in case $\mathrm{A}$ the variables $c_{0}, c_{1}, c_{2}, c_{3}, x_{\max }$, and $w_{\max }$ are being looked for meeting conditions (4) and

$$
\begin{aligned}
& w^{\prime}\left(x_{\max }\right)=0 ; \\
& w\left(x_{\max }\right)=w_{\max } .
\end{aligned}
$$

In case $\mathrm{B}$, the constants $c_{1}$ and $c_{3}$ will be zero and $c_{0}=$ $w_{\max }$. Only (10) and (12) are being solved, where the variables $c_{0}$ and $c_{2}$ are being looked for. The axial force can be directly computed by (15).

In case $\mathrm{C}$, there is a problem with determination of a maximum deflection placement. Logically, the maximum deflection will be in the middle of the rod. The angle of a rod rotation will be taken into account by computation. Owing to this, the placement of maximum deflection will be moved down, which is not important because it does not have any effect on the axial force computation. Four variables $c_{0}, c_{1}, c_{2}$, and $c_{3}$ are being looked for meeting the boundary conditions (6).

All three tasks lead to the solution of a system of nonlinear equations. It is important to determine upper limit of the sum, because to compute the sum to infinity is impossible and it is not needed. If the solution exists then the individual members of the sum decrease with the increasing step and at the certain value of step they will be negligible. We have the experience that after 10-14 steps the error will not be over $1 \%$. Newton method was used to solve these systems of nonlinear equations.

The computations were verified by the Runge-Kutta numerical method meeting the boundary conditions, which leads to the system of nonlinear equations as well. New function values $w_{1}(x), w_{2}(x), w_{3}(x)$, and $w_{4}(x)$ with a step $h$ are computed as

$$
\begin{aligned}
& w_{j, i+1}=w_{j, i}+k_{j, i} \\
& \qquad \text { for } j=1,2,3,4, i=0, \ldots,(l-1),
\end{aligned}
$$

where

$$
\begin{aligned}
k_{j, i}= & \frac{1}{6}\left(k_{j, i, 1}+2 k_{j, i, 2}+2 k_{j, i, 3}+k_{j, i, 4}\right), \\
k_{j, i, 1} & =h \cdot f_{j}\left(x_{i}, w_{1, i}, w_{2, i}, w_{3, i}, w_{4, i}\right), \\
k_{j, i, 2} & =h \cdot f_{j}\left(x_{i}+\frac{1}{2} h, w_{1, i}+\frac{1}{2} k_{1, i, 1}, w_{2, i}\right. \\
& \left.+\frac{1}{2} k_{2, i, 1}, w_{3, i}+\frac{1}{2} k_{3, i, 1}, w_{4, i}+\frac{1}{2} k_{4, i, 1}\right), \\
k_{j, i, 3} & =h \cdot f_{j}\left(x_{i}+\frac{1}{2} h, w_{1, i}+\frac{1}{2} k_{1, i, 2}, w_{2, i}\right. \\
& \left.+\frac{1}{2} k_{2, i, 2}, w_{3, i}+\frac{1}{2} k_{3, i, 2}, w_{4, i}+\frac{1}{2} k_{4, i, 2}\right), \\
k_{j, i, 4} & =h \cdot f_{j}\left(x_{i}+h, w_{1, i}+k_{1, i, 3}, w_{2, i}+k_{2, i, 3}, w_{3, i}\right. \\
& \left.+k_{3, i, 3}, w_{4, i}+k_{4, i, 3}\right) .
\end{aligned}
$$

The computation of the axial forces was also performed by CREO Simulate software.

\section{Results and Discussion}

Figures 8,9 , and 10 show the measured and computed values of the axial forces. Meaning of the labels are as follows: 12, 14: column diameter; EXP: experimental data; DR-E: analytically solved values; DR-N: numerically solved values; CREO: software solution. Figures 11, 12, 13, and 14 show how the axial force decreases with an increasing of the connecting holes eccentricity.

In Figures 15 and 16, the stress distribution in a place around the flattening is shown as a result of nonoverloaded stress in these places.

The maximum, average, and minimum discrepancies between the computation and experiment are shown in Tables 3-5. These discrepancies were calculated as relative errors between the average experimental values and calculated values with respect to the average experimental value. Moreover, the percentiles of $95 \%, 50 \%$, and $5 \%$ are given in Tables 3-5.

In the previous text, analytical solutions and numerical results for the maximum axial force of the steel tubes with flattened ends and connecting holes eccentricity are presented and compared with those obtained from experimental tests. Analytical solutions were derived with the moment of inertia approximated by a polynomial of 2 nd degree. Increasing of polynomial degree does not have to make better solution. Due to a small coefficient at the highest power (in order of $10^{-40}$ ), some mistakes can appear easily there. Due to the 


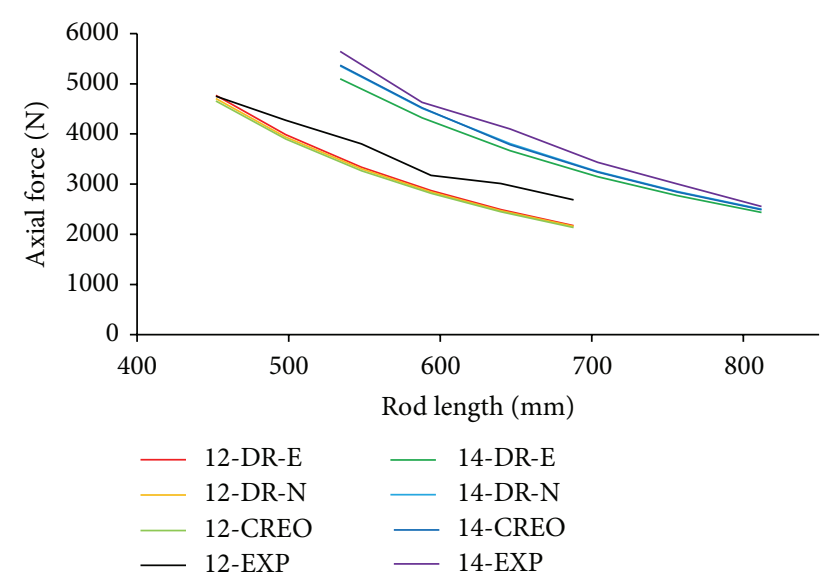

Figure 8: The measured and computed axial forces, A.

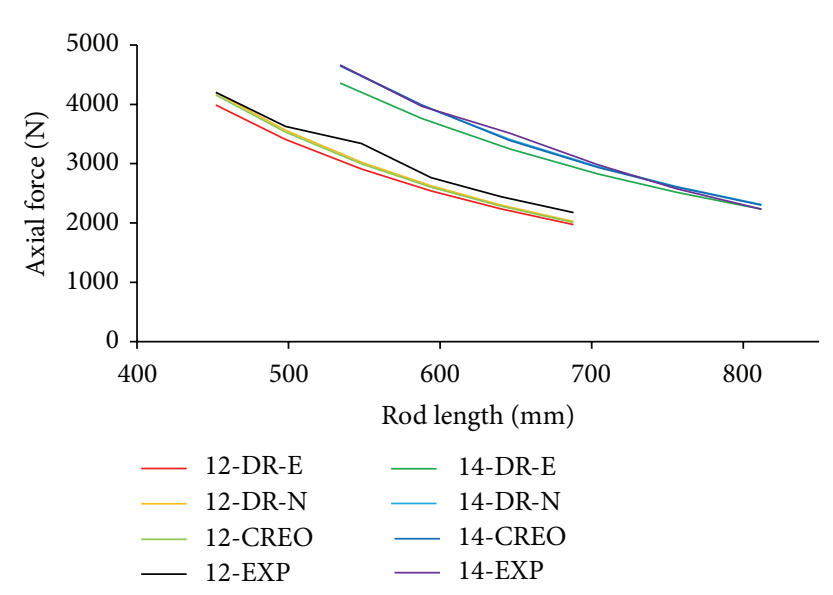

FIgURE 9: The measured and computed axial forces, B.

small differences, 2nd degree polynomial is sufficient in all investigated cases and solutions are presented only for the quadratic approximation.

Numerical solutions were also obtained by the RungeKutta method with the moment of inertia measured at the specific points. For purposes of comparison, simulations in CREO Simulate software are also presented. Figures 8-10 show the variation of the axial force with the length of steel tubes for the diameter $d_{\text {ext }}=12$ and $14 \mathrm{~mm}$. For cases $A$ and B, it can be seen in Figures 8 and 9 that the computed axial forces are underestimated by either analytical or numerical methods in comparison with the experimental results in both diameters. On the basis of results, it cannot be strictly said which method of computation is more accurate. In case $A$ and diameter $d_{\text {ext }}=12 \mathrm{~mm}$ and in case $C$, the analytical method is closer to the experiment. In the other cases, it is numerical method. Discrepancies between the individual methods are not significantly high and they can be considered as equivalent. Nevertheless, numerical method is more suitable than analytical method from the accuracy point of view. Considering the speed of calculation, we recommend analytical method for use.

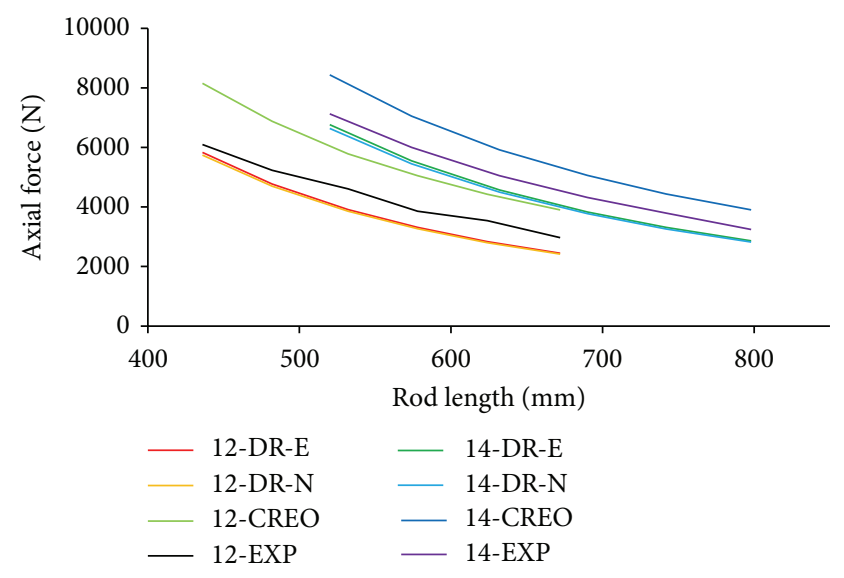

FIgURE 10: The measured and computed axial forces, C.

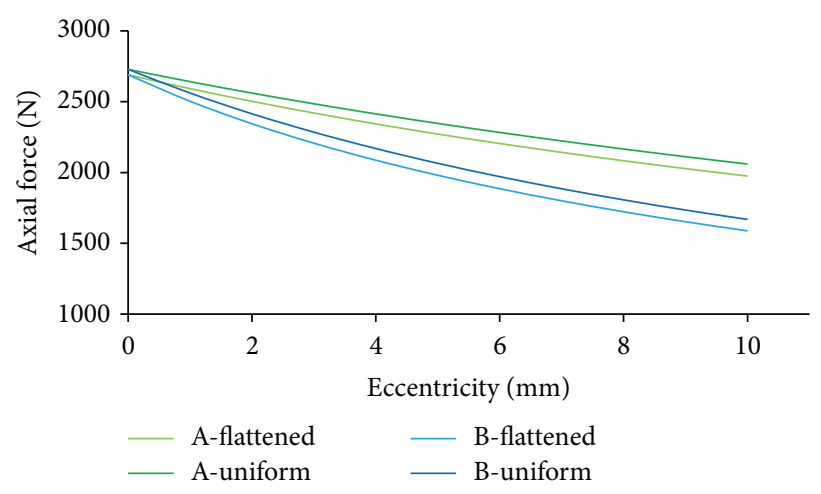

FIGURE 11: Dependence of the axial force and eccentricity (14/812).

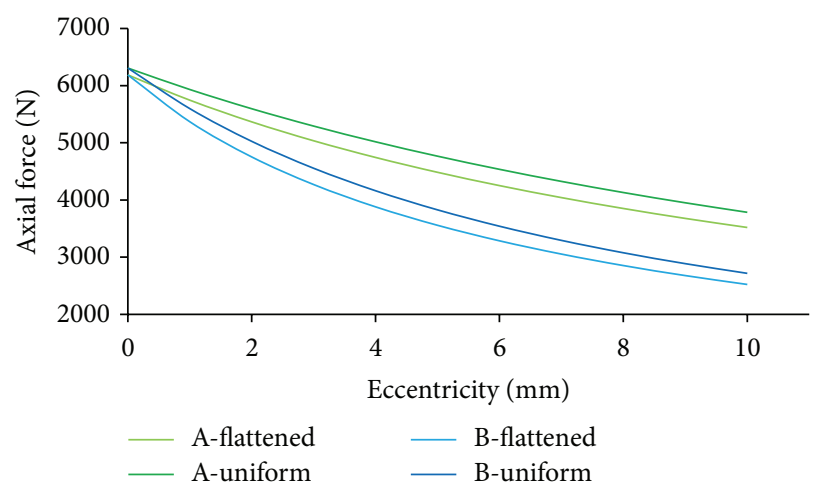

FIGURE 12: Dependence of the axial force and eccentricity (14/534).

Generally, discrepancies in case A are higher than in case $\mathrm{B}$ owing to the more complicated distribution of a bending moment, which was simplified in our mathematical model. Discrepancies at the diameter of $d_{\text {ext }}=12 \mathrm{~mm}$ are generally higher than at the diameter of $d_{\text {ext }}=14 \mathrm{~mm}$. It relates to the other loading parts which affect the smaller component parts rather. The results obtained by CREO Simulate software are closer to the numerical results and also can be considered as meaningful. Considering the column with the uniform cross section, differences between the numerical values and the 


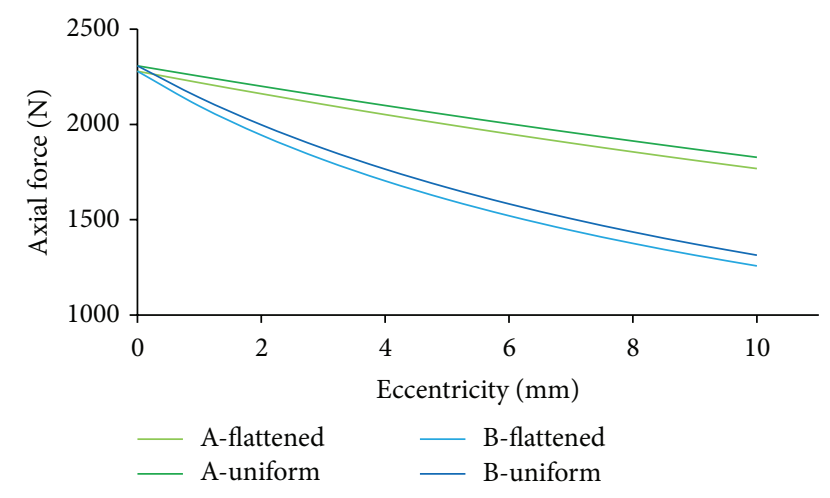

FIgURE 13: Dependence of the axial force and eccentricity (12/688).

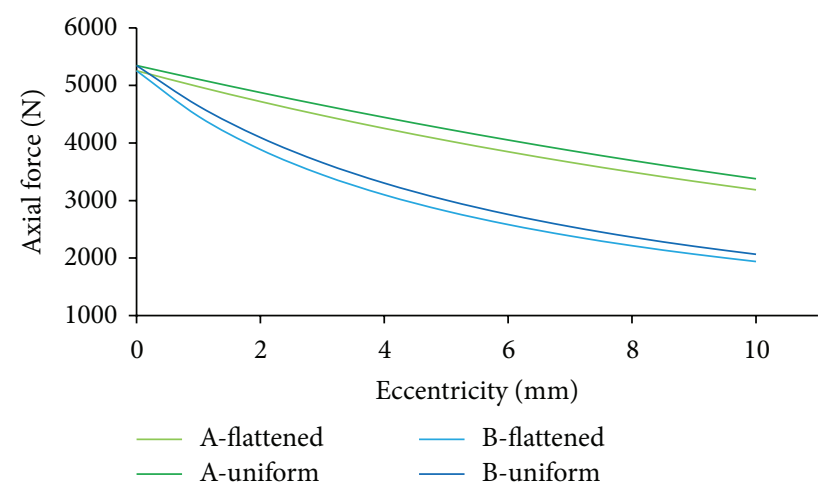

FIGURE 14: Dependence of the axial force and eccentricity (12/452).

values for uniform column are negligible and these values are not shown in figures.

Figure 10 shows that computed axial forces in the case $\mathrm{C}$ are more different from the experimental results than in cases $\mathrm{A}$ and $\mathrm{B}$. These differences are caused by a different character of deformation during the experiment. The columns behaved like clamped columns and were being deformed in a plane perpendicularly to a plane of natural rotation.

In Figures 11-14, the courses of the axial force in dependence on the connecting holes eccentricity are shown. There are the courses for both diameters and for the longest and the shortest specimen. The results show that, in all cases, the highest increase of the force is in the beginning of the eccentricity interval with subsequent equalization. The figures show that even small eccentricity of the hole is dangerous. For a comparison, the computations of a uniform column were also performed.

In case $\mathrm{A}$, there is lower decline of the axial force than in case $\mathrm{B}$, where the higher decline is in the case of flattened tubes unlike the uniform tubes. At the diameter $d_{\mathrm{ext}}=$ $14 \mathrm{~mm}$, the decline of the axial force is higher than at the diameter $d_{\text {ext }}=12 \mathrm{~mm}$. At longer columns, the decline is lower than at shorter columns. It follows that the lowest part of the axial force is lost in case $\mathrm{A}$ with the diameter $d_{\text {ext }}=$ $12 \mathrm{~mm}$ and $l=688 \mathrm{~mm}$, approximately $2.5 \%$ of the carrying capacity per $1 \mathrm{~mm}$ of eccentricity. The biggest part of the axial
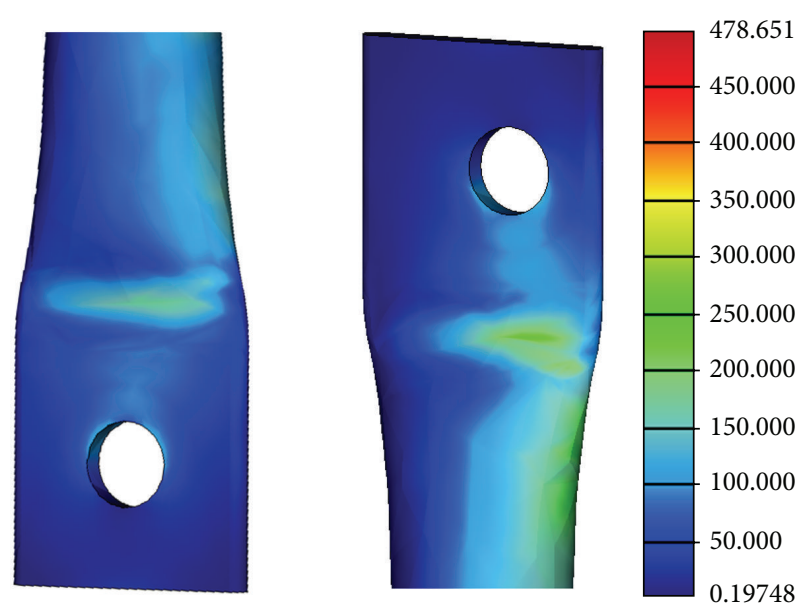

FIGURE 15: The stress distribution around the flattening, case A.
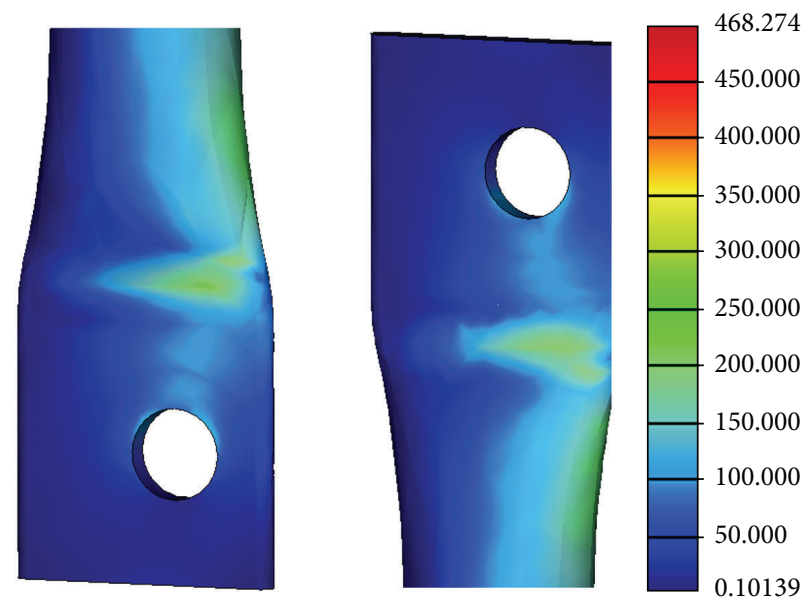

FIGURE 16: The stress distribution around the flattening, case B.

force is lost in case B with the diameter $d_{\text {ext }}=12 \mathrm{~mm}$ and $l=452 \mathrm{~mm}$, approximately $15 \%$ of the carrying capacity per first $1 \mathrm{~mm}$ of eccentricity, where this decline is continuously decreasing.

A mistake in a form of eccentricity up to $3 \mathrm{~mm}$ is common in the practice. In our cases, it means the following. In case A, the decline of the axial force is around $7-15 \%$ of the origin value, and in case B it is around $18-35 \%$ in dependence on the tube parameters. In case $\mathrm{C}$, there was not any loss of the carrying capacity, because the value of eccentricity was the same at both tube ends but in opposite side. Owing to the different behaviour of a tube deformation during the experiment, it is useless to develop our theory. When we have knowledge of one connecting hole eccentricity, it is suitable to drill the second one in opposite side about the same value of eccentricity, where there is no losing of the carrying capacity. In most cases, the value of axial force increased against the computed value. 
TABLE 3: The average and minimum discrepancies, case A.

\begin{tabular}{ccccc}
\hline$d_{\text {ext }}(\mathrm{mm})$ & & $\begin{array}{c}\text { Analytic } \\
\text { experiment }\end{array}$ & $\begin{array}{c}\text { Numeric } \\
\text { experiment }\end{array}$ & $\begin{array}{c}\text { CREO } \\
\text { experiment }\end{array}$ \\
\hline \multirow{4}{*}{12} & Minimum & $0.370 \%$ & $0.989 \%$ & $2.003 \%$ \\
& Average & $10.860 \%$ & $11.659 \%$ & $12.540 \%$ \\
& Maximum & $19.139 \%$ & $19.650 \%$ & $20.537 \%$ \\
& 5\% perc. & $0.370 \%$ & $0.989 \%$ & $2.003 \%$ \\
& 50\% perc. & $10.867 \%$ & $11.778 \%$ & $12.613 \%$ \\
& 95\% perc. & $19.139 \%$ & $19.650 \%$ & $20.537 \%$ \\
\hline \multirow{4}{*}{14} & Minimum & $4.638 \%$ & $2.114 \%$ & $2.311 \%$ \\
& Average & $7.944 \%$ & $4,590 \%$ & $4.760 \%$ \\
& Maximum & $10.516 \%$ & $7.142 \%$ & $7.618 \%$ \\
& 5\% perc. & $4.638 \%$ & $2.114 \%$ & $2.311 \%$ \\
& 50\% perc. & $8.080 \%$ & $5.121 \%$ & $5.201 \%$ \\
& 95\% perc. & $10.516 \%$ & $7.142 \%$ & $7.618 \%$ \\
\hline
\end{tabular}

TABLE 4: The average and minimum discrepancies, case B.

\begin{tabular}{ccccc}
\hline$d_{\text {ext }}(\mathrm{mm})$ & & $\begin{array}{c}\text { Analytic } \\
\text { experiment }\end{array}$ & $\begin{array}{c}\text { Numeric } \\
\text { experiment }\end{array}$ & $\begin{array}{c}\text { CREO } \\
\text { experiment }\end{array}$ \\
\hline \multirow{4}{*}{12} & Minimum & $5.093 \%$ & $0.147 \%$ & $1.061 \%$ \\
& Average & $8.316 \%$ & $4.845 \%$ & $5.678 \%$ \\
& Maximum & $12.886 \%$ & $9.519 \%$ & $10.342 \%$ \\
& 5\% perc. & $5.093 \%$ & $0.147 \%$ & $1.061 \%$ \\
& 50\% perc. & $8.272 \%$ & $5.328 \%$ & $6.149 \%$ \\
& 95\% perc. & $12.886 \%$ & $9.519 \%$ & $10.342 \%$ \\
\hline \multirow{4}{*}{14} & Minimum & $0.008 \%$ & $0.298 \%$ & $0.133 \%$ \\
& Average & $4.468 \%$ & $1.619 \%$ & $1.627 \%$ \\
& Maximum & $7.619 \%$ & $3.470 \%$ & $3.488 \%$ \\
& 5\% perc. & $0.008 \%$ & $0.298 \%$ & $0.133 \%$ \\
& 50\% perc. & $5.167 \%$ & $1.277 \%$ & $1.270 \%$ \\
& 95\% perc. & $7.619 \%$ & $3.470 \%$ & $3.488 \%$ \\
\hline
\end{tabular}

\section{Conclusion}

The maximum axial forces of a steel tube with flattened ends and eccentric connection were studied analytically and experimentally for different lengths and diameters. In the past, the experiment with connecting holes located in a rod axis was performed. Creating the holes, manufacturing mistakes can appear there and these holes can be drilled out of a rod axis. In this paper, the mathematical model was built which is the same in all cases of eccentricity. The differences are only in the boundary conditions.

In case $\mathrm{A}$, only an eccentricity of one connecting hole was considered. In case B, an eccentricity of both holes into the same side was considered. Logically, the measured values of force were lower than in case A. When manufacturing the holes and one is drilled with an eccentricity, we were interested in if it is more suitable to drill the second hole in the axis or to drill it out of the axis in opposite side (case C).
TABle 5: The average and minimum discrepancies, case C.

\begin{tabular}{ccccc}
\hline$d_{\text {ext }}(\mathrm{mm})$ & & $\begin{array}{c}\text { Analytic } \\
\text { experiment }\end{array}$ & $\begin{array}{c}\text { Numeric } \\
\text { experiment }\end{array}$ & $\begin{array}{c}\text { CREO } \\
\text { experiment }\end{array}$ \\
\hline \multirow{4}{*}{12} & Minimum & $4.343 \%$ & $5.836 \%$ & $25.020 \%$ \\
& Average & $13.331 \%$ & $14.512 \%$ & $29.635 \%$ \\
& Maximum & $19.808 \%$ & $20.802 \%$ & $33.718 \%$ \\
& 5\% perc. & $4.343 \%$ & $5.836 \%$ & $25.020 \%$ \\
& 50\% perc. & $14.709 \%$ & $15.855 \%$ & $31.033 \%$ \\
& 95\% perc. & $19.808 \%$ & $20.802 \%$ & $33.718 \%$ \\
\hline \multirow{4}{*}{14} & Minimum & $5.081 \%$ & $6.868 \%$ & $16.849 \%$ \\
& Average & $9.632 \%$ & $11.109 \%$ & $17.883 \%$ \\
& Maximum & $12.724 \%$ & $14.024 \%$ & $20.338 \%$ \\
& 5\% perc. & $5.081 \%$ & $6.868 \%$ & $16.849 \%$ \\
& 50\% perc. & $10.379 \%$ & $11.826 \%$ & $17.364 \%$ \\
& 95\% perc. & $12.724 \%$ & $14.024 \%$ & $20.338 \%$ \\
\hline
\end{tabular}

The experiment verified that the value of force is higher than in case A, which means that it is more suitable to drill the second hole in opposite side. Computing the forces, we can say the fact that even a small change of eccentricity causes a high change of the value of force.

\section{Glossary}

$\begin{array}{ll}a_{0}, a_{1}: & \text { Polynomial coefficients for } I \\ A: & \text { Area of the cross section }\left(\mathrm{m}^{2}\right) \\ c: & \text { Polynomial coefficients for } w \\ d_{\text {ext }}: & \text { External column diameter }(\mathrm{m}) \\ d_{\text {int }}: & \text { Internal column diameter }(\mathrm{m}) \\ e: & \text { Connection eccentricity }(\mathrm{m}) \\ E: & \text { Young's modulus }(\mathrm{Pa}) \\ h: & \text { Step size }(\mathrm{m}) \\ I: & \text { Moment of inertia }\left(\mathrm{m}^{4}\right) \\ k_{1}, k_{2}, k_{3}, k_{4}: & \text { Substitution functions } \\ l: & \text { Column length }(\mathrm{m}) \\ n: & \text { Polynomial exponent for } I \\ N: & \text { Axial force }(\mathrm{N}) \\ s_{j}, t_{j}: & \text { Substitution functions } \\ S: & \text { Section modulus }\left(\mathrm{m}^{3}\right) \\ w: & \text { Column deflection in } z \text {-axis }(\mathrm{m}) \\ w_{1}, w_{2}, w_{3}, w_{4}: & \text { Substitution functions } \\ w_{\max }: & \text { Maximum column deflection }(\mathrm{m}) \\ x, y, z: & \text { Coordinates } \\ x_{\max }: & \text { Position of } w_{\max }(\mathrm{m}) \\ \lambda: & \text { Eigenvalue }\left(\mathrm{m}^{-2}\right) \\ \sigma: & \text { Yield strength }(\mathrm{Pa}) .\end{array}$

\section{Competing Interests}

The authors declare that there is no conflict of interests regarding the publication of this paper. 


\section{Acknowledgments}

The paper has been written on the basis of research intention and solution of the research grant projects: KEGA č.019TU Z-4/2015 "Innovation Forms and Methods of the Educational Process in the Field of Agricultural and Forestry Equipment" and VEGA 1/0826/15 "Research of Cutting Mechanisms in the Processing Wood Materials.”

\section{References}

[1] A. El-Sheikh, "New space truss system-from concept to implementation," Engineering Structures, vol. 22, no. 9, pp. 10701085, 2000.

[2] G. S. Ramaswamy, M. Eekhout, and G. R. Suresh, Analysis, Design and Construction of Steel Space Frames, Thomas Telford Publishing, London, UK, 2002.

[3] C. A. S. De Freitas, L. M. Bezerra, and R. S. Y. De Silva, "Numerical and experimental study of steel space truss with stamped connection," Journal of Civil Engineering and Architecture, vol. 5, no. 6, pp. 494-504, 2011.

[4] J. M. Portolés, M. L. Romero, J. L. Bonet, and F. C. Filippou, "Experimental study of high strength concrete-filled circular tubular columns under eccentric loading," Journal of Constructional Steel Research, vol. 67, no. 4, pp. 623-633, 2011.

[5] K. H. Law and L. Gardner, "Buckling of elliptical hollow section members under combined compression and uniaxial bending," Journal of Constructional Steel Research, vol. 86, pp. 1-16, 2013.

[6] O. Zhao, L. Gardner, and B. Young, "Buckling of ferritic stainless steel members under combined axial compression and bending," Journal of Constructional Steel Research, vol. 117, pp. 35-48, 2016.

[7] M. A. El Aghoury, A. H. Salem, M. T. Hanna, and E. A. Amoush, "Strength of cold formed battened columns subjected to eccentric axial compressive force," Journal of Constructional Steel Research, vol. 113, pp. 58-70, 2015.

[8] X. Wang, J. Liu, and S. Zhang, "Behavior of short circular tubedreinforced-concrete columns subjected to eccentric compression," Engineering Structures, vol. 105, pp. 77-86, 2015.

[9] Y. Yang, Y. Wang, F. Fu, and J. Liu, "Static behavior of T-shaped concrete-filled steel tubular columns subjected to concentric and eccentric compressive loads," Thin-Walled Structures, vol. 95, pp. 374-388, 2015.

[10] X. Zhou, B. Yan, and J. Liu, "Behavior of square tubed steel reinforced-concrete (SRC) columns under eccentric compression," Thin-Walled Structures, vol. 91, pp. 129-138, 2015.

[11] A. Rashedi, I. Sridhar, K. J. Tseng, and N. Srikanth, "Minimum mass design of thin tubular structures under eccentric compressive loading," Thin-Walled Structures, vol. 90, pp. 191-201, 2015.

[12] "Constructional design of lifting device," SK Utility Model 1792013, Technical University in Zvolen, Zvolen, Slovakia, 2013, http://registre.indprop.gov.sk/registre/pdf/uv/6000/6901.pdf.

[13] S. Kotšmíd, M. Minárik, and P. Beňo, "Comparison of the experimental and theoretical critical buckling force at the rod of a defined shape," TTEM Journal, vol. 10, pp. 139-143, 2015.

[14] S. Kotšmíd, P. Beňo, and D. Kozak, "Effect of a tube flattening on the value of critical buckling force," in Proceedings of the 8th International Congress of Croatian Society of Mechanics, p. 8, Opatija, Croatia, September-October 2015.

[15] S. Kotšmíd, P. Beňo, D. Kozak, and G. Królczyk, "Methodology for the computation of critical buckling force at steel tubes with flattened ends," in Proceedings of the 7th International Scientific and Expert Conference, pp. 107-109, Belgrade, Serbia, 2015. 


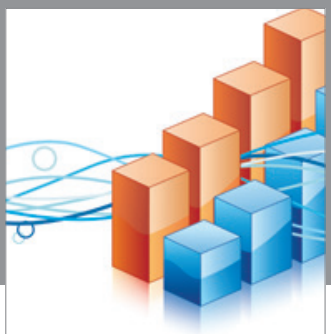

Advances in

Operations Research

vatem alat4

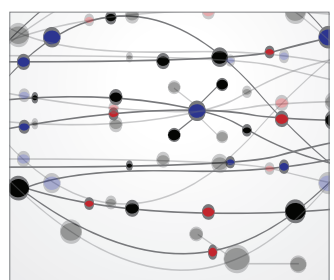

\section{The Scientific} World Journal
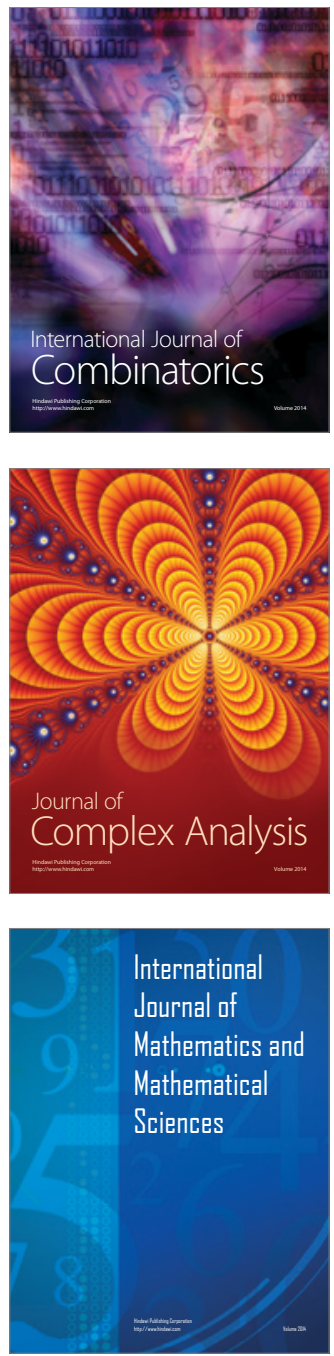
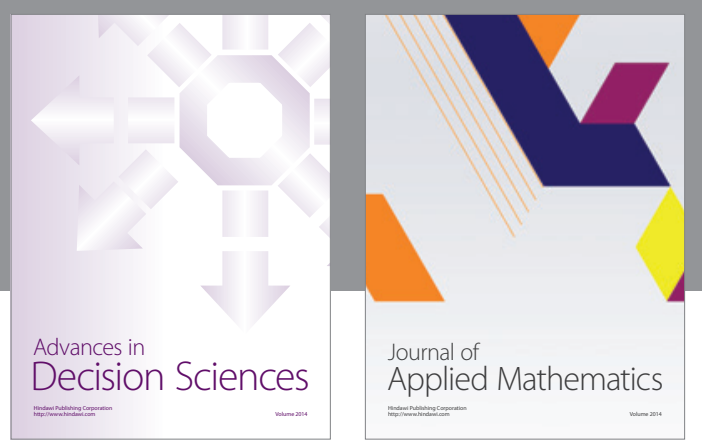

Algebra

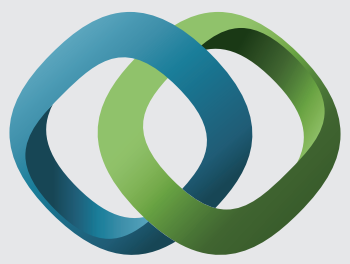

\section{Hindawi}

Submit your manuscripts at

http://www.hindawi.com
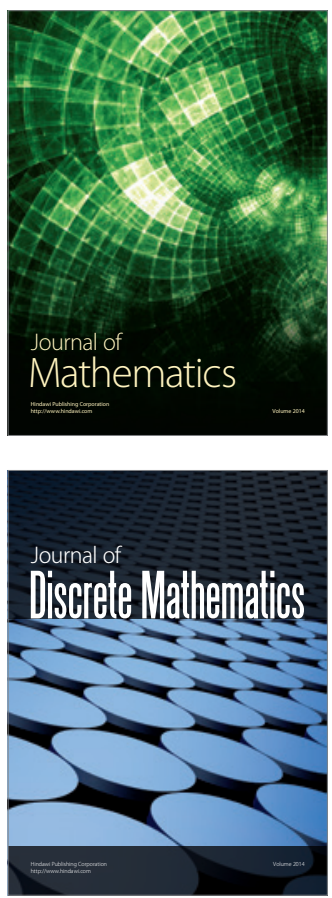

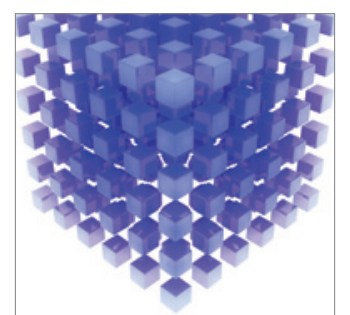

Mathematical Problems in Engineering
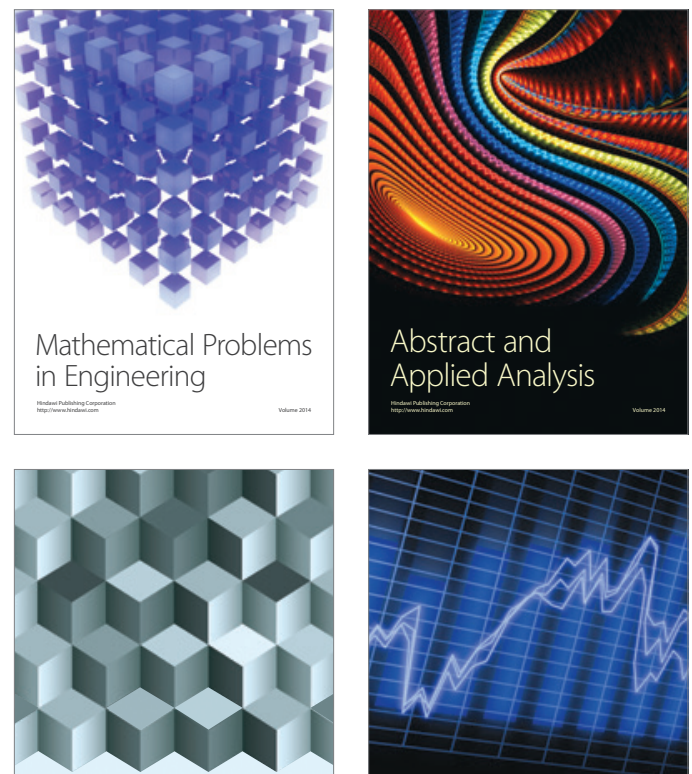

Journal of

Function Spaces

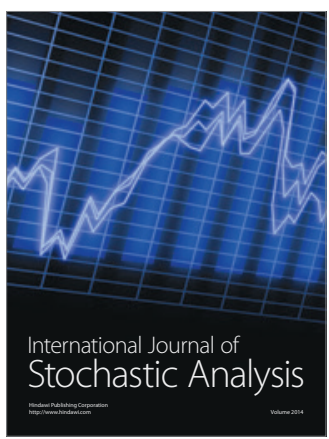

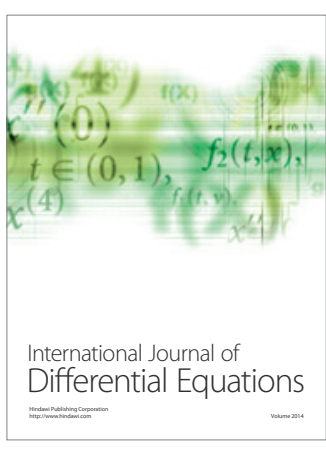
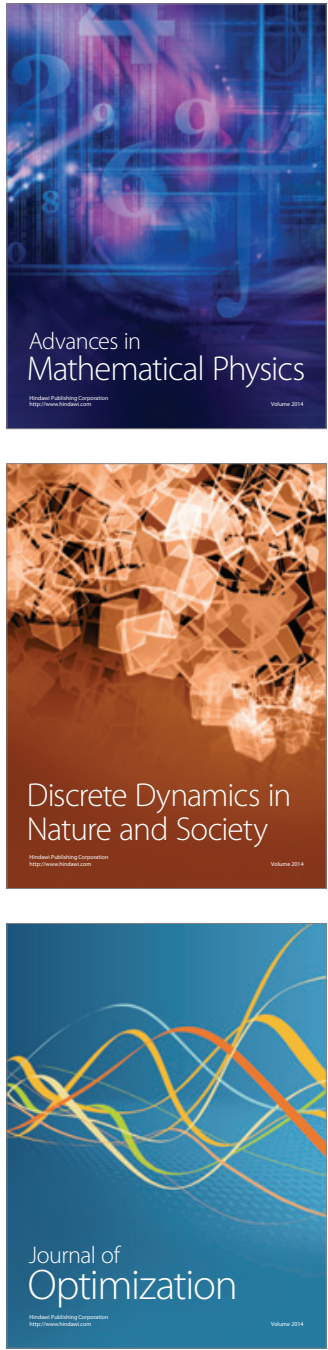